\title{
Healthcare Costs for People with Serious Mental Illness in England: An Analysis of Costs Across Primary Care, Hospital Care, and Specialist Mental Healthcare
}

\author{
Jemimah Ride ${ }^{1}\left[\begin{array}{l}\text { D } \\ \text { Panagiotis Kasteridis }\end{array}\right.$
}

Published online: 8 November 2019

(c) The Author(s) 2019

\begin{abstract}
Background Serious mental illness (SMI) is a set of disabling conditions associated with poor outcomes and high healthcare utilisation. However, little is known about patterns of utilisation and costs across sectors for people with SMI.

Objective The aim was to develop a costing methodology and estimate annual healthcare costs for people with SMI in England across primary and secondary care settings.

Methods A retrospective observational cohort study was conducted using linked administrative records from primary care, emergency departments, inpatient admissions, and community mental health services, covering financial years 2011/122013/14. Costs were calculated using bottom-up costing and are expressed in 2013/14 British pounds (GBP). Determinants of annual costs by sector were estimated using generalised linear models.

Results Mean annual total healthcare costs for 13,846 adults with SMI were $£ 4989$ (median $£ 1208$ ), comprising $19 \%$ from primary care ( $£ 938$, median $£ 531$ ), $34 \%$ from general hospital care ( $£ 1717$, median $£ 0$ ), and $47 \%$ from inpatient and community-based specialist mental health services ( $£ 2334$, median $£ 0$ ). Mean annual costs related specifically to mental health, as distinct from physical health, were $£ 2576$ (median £290). Key predictors of total cost included physical comorbidities, ethnicity, neighbourhood deprivation, SMI diagnostic subgroup, and age. Some associations varied across care context; for example, older age was associated with higher primary care and hospital costs, but lower mental healthcare costs.

Conclusions Annual healthcare costs for people with SMI vary significantly across clinical and socioeconomic characteristics and healthcare sectors. This analysis informs policy and research, including estimation of health budgets for particular patient profiles, and economic evaluation of health services and policies.
\end{abstract}

Electronic supplementary material The online version of this article (https://doi.org/10.1007/s40258-019-00530-2) contains supplementary material, which is available to authorized users.

Jemimah Ride

jemimah.ride@unimelb.edu.au

Panagiotis Kasteridis

panos.kasteridis@york.ac.uk

Nils Gutacker

nils.gutacker@york.ac.uk

Maria Jose Aragon Aragon

mariajose.aragonaragon@york.ac.uk

Rowena Jacobs

rowena.jacobs@york.ac.uk

1 Health Economics Unit, Melbourne School of Population and Global Health, University of Melbourne, Level 4, 207

Bouverie Street, Parkville, VIC 3010, Australia

2 Centre for Health Economics, University of York, York, UK

\section{Key Points for Decision Makers}

This is the first documentation of the spectrum of healthcare costs across sectors for people with serious mental illness (SMI) using individual-level data.

People utilising care for SMI incur high healthcare costs, although there is substantial variation across the care pathway.

Understanding which patient profiles incur costs in which sectors can help policymakers plan health budgets and inform policy levers to manage resource use across the care pathway. 


\section{Introduction}

\subsection{Background/Rationale}

Serious mental illness (SMI) comprises a set of chronic conditions that affect mood, emotion, cognition and motivation and all aspects of life including employment, relationships, housing, and personal care [1]. UK healthcare policy defines SMI as schizophrenia, bipolar disorder, and other nonorganic psychoses [2]; $0.72 \%$ of the population in England will receive a diagnosis of schizophrenia at some point in their lives [3], and 1-2\% will receive a diagnosis of bipolar disorder [4]. People with SMI have poorer physical health compared to the general population, with a higher prevalence of common chronic disorders and multi-morbidity, and a lower life expectancy by around 20 years, and often die of preventable physical illnesses [5-9]. People with SMI have high rates of healthcare utilisation, including accident and emergency (A\&E) attendances and hospital admissions, for both physical and mental health problems [10-13], and the multiplicity of co-morbid health conditions raises total healthcare costs [14].

A number of studies have examined the direct costs of SMI to the healthcare system as well as the wider indirect costs to society [15-22]. Direct costs include the use of hospital services, drugs, staff time, ambulances, and community care; for schizophrenia alone these costs can range from 0.5 to $3.5 \%$ of national healthcare expenditures [19]. Indirect costs include reduced labour supply, premature mortality, reduced health-related quality of life, lost output, lost tax revenue, transfer payments, and unpaid care by family or friends [21]. The total monetary costs in England for schizophrenia and psychoses have been estimated at $£ 11.8$ billion in 2012 , and for bipolar disorder, they have been estimated at $£ 5.2$ billion in 2007 (equivalent to $£ 6.04$ billion in 2012).

Studies have used different costing methodologies to estimate direct costs of mental health treatment and the main cost drivers thereof. Cost estimation studies tend to use a gross-costing methodology that often reflects reimbursement amounts, whereas micro-costing methods involve the enumeration of all resources consumed by a patient. A systematic review by Wolff et al. [23] examining the association between mental healthcare hospital costs and patient characteristics considered costing approaches in mental healthcare more broadly, not just for SMI. It found that studies differed in their estimation of resource use and valuation. The paper also identified six patient characteristics as key cost drivers of hospital costs, one being the presence of psychotic or affective symptoms. Studies using a micro-costing approach $[24,25]$ focused on examining differences in characteristics between high-cost users and the rest of the cost distribution.
These show that high-cost users of mental healthcare (incurring the top $10 \%$ of costs) account for a disproportionately large share of healthcare costs (74-87\%), and that the majority have a diagnosis of SMI (particularly schizophrenia).

Despite the considerable disease burden and costs for this patient group, there has been little empirical cost estimation research specifically focusing on the SMI population, using linked individual-level data and micro-costing approaches, and analysing data for more than 1 year. A further gap in the literature has been the estimation of multi-sectoral costs for people with SMI examining which elements of the care pathway are the main cost drivers across sectors. Most studies examining cost drivers of patient care for this population group have focused on inpatient care and/or on total costs. Understanding where the largest components of cost fall across different sectors, as well as identifying the main cost drivers, is important to help design more cost-effective treatment pathways and more integrated care for this patient group.

We address these gaps in the evidence by seeking to (1) develop a costing methodology for multi-sectoral healthcare costs for people with SMI in England based on the best micro-level data currently available, (2) estimate annual healthcare costs for people with SMI in England across primary and secondary care, and (3) identify predictors of costs across each sector.

The key contributions of this study are that (1) it is the first study to use linked administrative records for the full care pathway of patients with SMI in the English National Health Service (NHS), covering primary care, emergency departments, inpatient admissions, and community mental health services; (2) it covers 3 financial years (2011/12-2013/14), where previous studies have tended to estimate costs for a single year; (3) it employs a detailed bottom-up costing methodology; and (4) it provides evidence on the key clinical and socio-economic cost drivers across different healthcare sectors.

\section{Methods}

\subsection{Study Design}

This observational cohort study used healthcare service administrative data from primary care, inpatient admissions, A\&E presentations, and community mental health services linked at the individual patient level. Annual costs of healthcare utilisation in each of these sectors was estimated using a bottom-up approach for 3 financial years from $2011 / 12$ to $2013 / 14$, applying national average unit costs for the 2013/14 financial year from the perspective of the NHS.

To provide some indication of the proportion of healthcare costs related to mental health as distinct from physical 
health for this population, we identified a subset of costs that could be clearly labelled as "related", comprising all specialist mental healthcare costs (inpatient and outpatient) and mental health drug costs in primary care.

\subsection{Data Source and Sample}

Data for this study were accessed through the Clinical Practice Research Datalink (CPRD), a dataset of records from primary care practices in the UK [26]. Data on all patients at participating practices are included unless a patient requests to have her/his data excluded. Practices in England can also allow their records to be linked to hospital records in the Hospital Episodes Statistics (HES) and community mental health service records in the Mental Health Minimum Dataset (MHMDS). ${ }^{1}$ CPRD data are broadly representative of the English population regarding age and gender [27]. CPRD provided anonymised primary care data of patients identified as having SMI based on Read codes ${ }^{2}$ in routinely recorded CPRD data, linked at the individual patient level to data from HES and MHMDS for those patients. Supplementary Table 1 provides the Read codes used to identify diagnostic categories of SMI; see the electronic supplementary material. Supplementary Figure 1 outlines how the sample was formulated for this study. Supplementary Table 2 provides an overview of the sources of utilisation data and unit costs. Supplementary Table 3 outlines the mean visit duration for primary care visits of different types.

\subsection{Primary Care Costs}

Primary care utilisation data were extracted from CPRD records based on Read codes for three types of primary care activity: consultations, drugs prescribed, and diagnostic tests.

Unit costs for consultations were obtained from national estimates of the cost per minute of general practitioner (GP) and practice nurse time for 2014 [29]. We used visit duration data rather than a standard visit cost because of evidence suggesting that consultations for patients with mental health problems are longer than average [30-33]. We considered multiple visits in a day for a patient to a single staff member as duplicates, but allowed for visits to different staff members on the same day. See the electronic supplementary material for additional detail.

The costs of drug prescriptions were derived from the Prescription Costs Analysis ${ }^{3}$ for 2014, which applied the British National Formulary (BNF) edition 66 [34] classification system. Prescription volume was taken from the Therapy section of the CPRD dataset. We used data at the BNF subparagraph level where available, otherwise at the most specific BNF level available (paragraph, section, or chapter level). ${ }^{4}$

National average unit costs for diagnostic tests were taken from the NHS Reference Costs for the financial year 2013/14 [35], calculated retrospectively each year to identify the full cost of diagnostic imaging, diagnostic services, pathology services, and outpatient procedures. Utilisation volume of each test was taken from Read terms recorded in the Test section of the CPRD dataset. These were classified following clinicians' advice into groups that corresponded to the NHS Reference Costs categories. ${ }^{5}$ Supplementary file Test_unit_allocations_and_costs.xlsx lists the Read terms and how they were classified into Reference Cost categories (see the electronic supplementary material).

\subsection{Community Mental Health Service Costs}

We used a subset of the activity recorded in MHMDS as measures of utilisation of community mental health services. Specifically, we counted healthcare professional contacts (consultations), Care Programme Approach (CPA) reviews, electroconvulsive therapy (ECT) sessions, and day attendances, and assigned unit costs reported by the Personal Social Services Research Unit (PSSRU) and the Electronic Staff Record [36].

The cost of consultations depends on the staff type and the duration of the contact (for details on how we dealt with missing and zero duration see the electronic supplementary material). Based on advice regarding usual practice, we restricted the number of consultations per day to a maximum of two for each type of staff member to avoid duplicate

\footnotetext{
1 This dataset has changed names over time; for the period we used, 2011/12-2013/14, it was called the Mental Health Minimum Dataset (MHMDS). In September 2014, it became the Mental Health and Learning Disabilities Data Set (MHLDDS). From 2016/17, it became the Mental Health Services Data Set (MHSDS). See http://webar chive.nationalarchives.gov.uk/20171011052615/http://content.digit al.nhs.uk/article/7439/Mental-Health-Services-Data-Set-ArchivedSpecification [accessed 21 February 2019].

${ }^{2}$ Read codes are a clinical coding system used in primary care in the UK to classify diseases, patient characteristics, procedures, and tests [28].
}

\footnotetext{
3 This provides the Net Ingredient Cost per item according to the Drug Tariff. It does not include any discounts, dispensing fees, or adjustment for income, and is based on the usual quantity dispensed for that drug.

${ }^{4}$ This approach did not account for other items listed in CPRD as "therapy" that are not included in the BNF, such as dressings or glucose test strips.

${ }^{5}$ For example, Read terms (descriptive terms attached to Read codes) for blood tests recorded in CPRD data included "Liver function test", and "Serum creatinine", which were both classified as "Clinical biochemistry".
} 
recordings. Regarding CPA reviews, MHMDS provides only the date and not the staff involved or duration. We assumed, following clinical advice, that reviews (which are supposed to be multidisciplinary) involve a psychiatrist and a nurse and last $30 \mathrm{~min}$, a lower bound estimate. Cost per ECT session was based on past costings updated to 2013/14 values using the hospital and community health services pay and price inflation series [37]. Day attendance cost was based on the cost of day care provided by local authority social services for people with mental health problems [29].

\subsection{Hospital Costs}

Admissions to specialist mental health inpatient facilities are recorded in MHMDS, and admissions to general hospitals (including admissions to non-specialist mental health providers) are recorded in HES. We costed these two separately using national average costs for the type of admission.

\subsubsection{Admissions to Specialist Mental Health Inpatient Facilities}

The cost of a specialist mental health admission depends on its duration and the category of mental health problem or needs (termed the "cluster") to which the patient is assigned, since the Reference Costs of admitted days vary by the 21 mental health clusters that exist in the classification system [35]. Admissions recorded in MHMDS cover all admissions to specialist mental health inpatient facilities and list duration, but not the cluster allocation. Instead, we used the closest start of a cluster episode ${ }^{6}$ or date of Mental Health Clustering Tool ${ }^{7}$ to determine the cluster. We excluded admissions with the same start and end dates as these were likely to represent recording errors, and for the $14 \%$ of admissions without an assigned cluster, we used a weighted average cost across all clusters. For further detail, see the electronic supplementary material.

\subsubsection{General Hospital Costs}

We identified inpatient hospital admissions and A\&E presentations from HES records. The classification system for hospital activity in England is Healthcare Resource Groups (HRGs), which are similar to Diagnosis-Related Groups (DRGs) used in other jurisdictions. In the electronic supplementary material, we explain how inpatient episodes of care and $A \& E$ attendances are grouped into HRGs reflecting type of activity (inpatient or A\&E HRGs), additional high-cost inpatient procedures, and long inpatient stays. Costs for these activities were taken from the hospital-reported Reference Costs.

The allocation of episodes to HRGs was carried out using the costing grouper software which is freely available on the NHS Digital website [40]. We grouped all the activity using the 2012/13 version of the HRGs design and the corresponding 2012/13 Reference Costs to obtain costs for each activity, then used the hospital and community health services pay and price inflation index [41] to express costs in 2013/14 prices. For episodes with missing or invalid essential data fields, the grouper returns an error HRG code. After minor adjustments and imputation of some non-essential fields, the error rate for our sample was reduced to about $7 \%$ for inpatient episodes and $10 \%$ for A\&E presentations. Although HES includes admissions to specialist mental health facilities, these were not costed because these were captured through MHMDS, but mental health conditions treated by non-specialist mental health providers (HRGs starting with "WD") were included in general hospital costs. Using the inpatient episode start and end dates, costs were apportioned into the financial years 2011/12-2013/14. Where an episode of care extended over 2 years, we attributed costs to each year based on the proportion of episode days in each of the 2 years.

\subsection{Explanatory Variables}

Read codes in CPRD data were used to identify patient characteristics. SMI diagnoses were grouped according to clinical advice into categories of "schizophrenia and other psychoses" and "bipolar disorder and affective psychosis", with some patients having diagnostic codes from both groups at different times. A variable was formulated to indicate the number of years since diagnosis when the patient entered observation in the study. The 2010 Index of Multiple Deprivation (IMD) quintile for the patient's area of residence served as an indicator of socioeconomic area deprivation. Based on the primary care practice location, two variables indicating the distance from the practice to the nearest acute hospital and inpatient mental health facility and another indicating the rurality category of the practice were derived. ${ }^{8}$

\footnotetext{
${ }^{8}$ Geographic information was derived by CPRD based on the patient residence and practice locations. These links were made by CPRD to avoid disclosing location information to the study team. Patient residence information was linked to IMD quintiles based on the lowerlayer super output area (LSOA) or small neighbourhood area.
}

${ }^{6}$ Cluster episode duration: The number of days that a patient has remained on the same cluster regardless of whether Mental Health Clustering Tool assessment reviews have taken place. See Annex B in NHS England [38].

7 The Mental Health Clustering Tool is an algorithm used to allocate patients to a cluster [39]. 


\subsection{Statistical Methods}

For each patient, event costs were aggregated into annual costs by sector and year, effectively obtaining a panel dataset of annual costs in primary care, specialist mental healthcare (including inpatient and community-based care), and general hospital care (including A\&E), with total costs as the sum of these three. To investigate patterns of total and sector costs across patient and practice characteristics, we compared mean costs and examined the distribution of costs in each group, and conducted multivariate regression analysis. Explanatory variables were based on factors associated with utilisation of healthcare in prior research [24, 25, 42]. We used a generalised linear model (GLM) with individual random effects, which allows for the non-normal distribution of healthcare costs and models the mean directly, avoiding the need to transform the data. The choices of distributional family and link function were informed by the Park test [43] and Pregibon link test [44]. All analyses were conducted in Stata v14 [45].

\subsection{Sensitivity Tests}

As an alternative to using the consultation duration data in CPRD and MHMDS, we estimated costs using the average duration for different types of consultations derived from the 2006/07 UK General Practice Workforce Survey that are applied by Curtis [29]. For mental health inpatient admissions, we present for comparison the results of costing bed days using the weighted average cost per bed day across all clusters from the national Reference Costs, rather than applying the cluster-specific cost.

To account for potential sex differences in the severity of schizophrenia [46] and bipolar disorder [47], we estimated the model including an interaction term between sex and diagnostic grouping.

\section{Results}

\subsection{Sample}

The sample consists of 34,484 year-observations across 13,846 adults with SMI for the financial years 2011/12-2013/14. Two-thirds of the sample (66.6\%) were observed for all 3 years, $15.8 \%$ were observed for 2 years and $17.6 \%$ were observed for one full financial year. Supplementary Figure 1 shows the numbers of patients at each stage of the sample formation.

The first data column of Table 1 shows the distribution of characteristics across the sample. The mean (median) age was $52(50)$ years, the majority (71\%) were white, around a third had at least one physical comorbidity, two-thirds had comorbid depression, three-quarters were current or exsmokers, and $16 \%$ had been recently diagnosed with SMI. People in the sample were more likely to live in urban areas (89\%) than rural areas, and in more deprived areas.

\subsection{Resource Use and Costs}

The mean annual healthcare cost per patient was $£ 4988.87$ (range $£ 0-243,831$ ), with $£ 2575.73$ (52\%) identifiable as related to SMI. Figure 1 shows that total costs decreased with age until middle age, and then increased for patients aged over 65 , while the proportion of costs related to SMI steadily decreased with age. For patients 19-35 years old, $64 \%$ of total costs were related to SMI, while for patients aged over 65 , the proportion was $36 \%$, reflecting a greater emphasis on management of physical comorbidities.

Table 1 shows that primary care costs (£938, range $£ 0-29,720$ ) made up approximately $19 \%$ of total mean annual costs, general hospital costs $(£ 1717$, range $£ 0-233,318$ ) comprised $34 \%$, and specialist mental healthcare costs (£2334, range $£ 0-176,502)$ accounted for $47 \%$. Table 2 outlines the annual utilisation of the different resource units making up these costs.

Table 1 also provides mean cost per year for subgroups of patients: mean total costs increase with age, level of deprivation, and number of comorbidities, and are higher for white than black or minority ethnicity patients, and for patients diagnosed with SMI more recently. Patients with both schizophrenia and bipolar-type disorders had higher costs than those with schizophrenia-type alone, with bipolartype associated with the lowest costs.

\subsection{Association of Characteristics with Costs}

The Pregibon test supported a log link for GLM $(p=0.104)$ with a Poisson distribution supported by the Park test $(p=0.483)$. The association of each patient and practice characteristic with the difference in total annual costs (marginal effects from random effects GLM) is presented in Table 3. After adjusting for other observable characteristics, higher costs for patients of white ethnicity (compared with black and minority ethnicities), those with higher socioeconomic deprivation, and those with physical comorbidities were still seen, as was the pattern of costs across diagnostic categories.

Table 3 shows how these patterns differ across healthcare sectors. White ethnicity and having SMI diagnoses from both categories were consistently associated with higher costs across all sectors. Socioeconomic deprivation was associated with higher primary care and mental health costs. Older patients had higher primary care and general hospital costs, but lower mental health costs. Physical comorbidity was associated with higher costs in primary care 
Table 1 Patient characteristics and mean annual healthcare cost by sector and total

\begin{tabular}{|c|c|c|c|c|c|c|c|c|c|}
\hline & \multirow[t]{2}{*}{$N$ individuals (\%) } & \multicolumn{2}{|c|}{ Total cost } & \multicolumn{2}{|c|}{$\begin{array}{l}\text { Primary care } \\
\text { cost }\end{array}$} & \multicolumn{2}{|c|}{$\begin{array}{l}\text { General hospital } \\
\text { cost }\end{array}$} & \multicolumn{2}{|c|}{$\begin{array}{l}\text { Mental health } \\
\text { service cost }\end{array}$} \\
\hline & & Mean & SD & Mean & SD & Mean & SD & Mean & SD \\
\hline Overall & 13,846 & 4989 & 14,349 & 938 & 1368 & 1717 & 6734 & 2334 & 10,021 \\
\hline \multicolumn{10}{|l|}{ Age } \\
\hline $19-35$ & 2595 (18.7) & 5429 & 16,819 & 562 & 951 & 1521 & 6303 & 3346 & 12,855 \\
\hline $36-45$ & $2835(20.5)$ & 4744 & 14,541 & 785 & 1223 & 1312 & 5825 & 2647 & 10,604 \\
\hline $46-55$ & 3025 (21.8) & 4747 & 13,659 & 977 & 1427 & 1370 & 5758 & 2401 & 9762 \\
\hline $56-65$ & $2358(17.0)$ & 4569 & 12,213 & 1094 & 1544 & 1777 & 6841 & 1698 & 7566 \\
\hline$\geq 66$ & 3033 (21.9) & 5473 & 14,380 & 1205 & 1472 & 2564 & 8426 & 1704 & 8817 \\
\hline \multicolumn{10}{|l|}{ Sex } \\
\hline Female & 7018 (50.7) & 4981 & 13,142 & 1097 & 1530 & 1760 & 5832 & 2124 & 9059 \\
\hline Male & $6828(49.3)$ & 4997 & 15,508 & 771 & 1153 & 1672 & 7561 & 2554 & 10,932 \\
\hline \multicolumn{10}{|l|}{ Ethnicity } \\
\hline Black, minority ethnicities & $3981(28.7)$ & 3340 & 13,014 & 665 & 999 & 1060 & 7399 & 1615 & 8533 \\
\hline White & $9865(71.3)$ & 5660 & 14,806 & 1049 & 1479 & 1985 & 6424 & 2627 & 10,553 \\
\hline \multicolumn{10}{|l|}{ Diagnostic grouping } \\
\hline Bipolar disorder and affective psychosis & $5086(36.7)$ & 4241 & 11,764 & 998 & 1302 & 1643 & 5988 & 1601 & 7549 \\
\hline Schizophrenia and other psychoses & $7122(51.4)$ & 5122 & 15,319 & 854 & 1340 & 1724 & 7411 & 2543 & 10,904 \\
\hline Both categories & $1638(11.8)$ & 6631 & 16,787 & 1100 & 1622 & 1903 & 5842 & 3628 & 12,203 \\
\hline \multicolumn{10}{|l|}{ Years since diagnosis } \\
\hline $0-1$ & $2221(16.0)$ & 5422 & 15,267 & 882 & 1331 & 1805 & 7271 & 2735 & 10,439 \\
\hline $2-5$ & $2673(19.3)$ & 4792 & 13,432 & 906 & 1378 & 1598 & 5729 & 2289 & 9738 \\
\hline$>5$ & $8952(64.7)$ & 4970 & 14,437 & 956 & 1372 & 1736 & 6901 & 2278 & 10,026 \\
\hline \multicolumn{10}{|l|}{ Index of multiple deprivation quintile } \\
\hline 1 , least deprived & $2226(16.1)$ & 4244 & 12,975 & 878 & 1247 & 1532 & 6551 & 1834 & 8588 \\
\hline 2 & $2547(18.4)$ & 4534 & 12,808 & 897 & 1240 & 1670 & 6010 & 1967 & 8658 \\
\hline 3 & $2526(18.2)$ & 5183 & 14,997 & 944 & 1414 & 1809 & 6611 & 2430 & 10,766 \\
\hline 4 & $3246(23.4)$ & 5115 & 14,087 & 976 & 1407 & 1695 & 6165 & 2445 & 10,022 \\
\hline 5 , most deprived & $3301(23.8)$ & 5582 & 16,017 & 967 & 1464 & 1831 & 7927 & 2873 & 11,242 \\
\hline \multicolumn{10}{|l|}{ Number of Charlson comorbidities } \\
\hline 0 & $8904(64.3)$ & 4610 & 14,237 & 733 & 1114 & 1405 & 5779 & 2472 & 10,477 \\
\hline 1 & $3716(26.8)$ & 5386 & 14,078 & 1160 & 1510 & 1987 & 7090 & 2239 & 9261 \\
\hline 2 & $885(6.4)$ & 6603 & 17,055 & 1758 & 2061 & 3133 & 11,852 & 1712 & 8867 \\
\hline 3 or more & $341(2.5)$ & 6840 & 12,037 & 1969 & 2027 & 3696 & 7708 & 1174 & 7848 \\
\hline \multicolumn{10}{|l|}{ Comorbid depression } \\
\hline No history of depression & $5274(38.1)$ & 4893 & 15,039 & 731 & 1098 & 1685 & 7725 & 2477 & 10,587 \\
\hline History of depression & $8572(61.9)$ & 5047 & 13,915 & 1063 & 1495 & 1736 & 6057 & 2248 & 9662 \\
\hline \multicolumn{10}{|l|}{ History of smoking } \\
\hline Non-smoker & $3186(23.0)$ & 4754 & 14,820 & 768 & 1018 & 1669 & 7723 & 2317 & 10,124 \\
\hline Current or ex-smoker & $10,660(77.0)$ & 5057 & 14,209 & 987 & 1451 & 1731 & 6418 & 2339 & 9992 \\
\hline \multicolumn{10}{|l|}{ Rurality of GP practice } \\
\hline Urban area & $12,267(88.6)$ & 5087 & 14,666 & 923 & 1331 & 1744 & 6934 & 2419 & 10,244 \\
\hline Rural area & $1579(11.4)$ & 4241 & 11,616 & 1049 & 1622 & 1507 & 4941 & 1685 & 8090 \\
\hline \multicolumn{10}{|c|}{ Distance from GP practice to nearest acute hospital } \\
\hline $0-3 \mathrm{~km}$ & $6093(44.0)$ & 5281 & 15,353 & 928 & 1388 & 1854 & 7602 & 2499 & 10,357 \\
\hline$>3-6 \mathrm{~km}$ & $3858(27.9)$ & 4840 & 14,003 & 879 & 1199 & 1639 & 6181 & 2322 & 10,072 \\
\hline$>6-9 \mathrm{~km}$ & $1739(12.5)$ & 4602 & 13,225 & 1020 & 1462 & 1628 & 6142 & 1954 & 9569 \\
\hline$>9 \mathrm{~km}$ & $2156(15.6)$ & 4750 & 12,841 & 1004 & 1507 & 1545 & 5430 & 2201 & 9301 \\
\hline $0-3 \mathrm{~km}$ & $2702(19.5)$ & 5209 & 15,244 & 918 & 1312 & 1822 & 7127 & 2468 & 10,482 \\
\hline
\end{tabular}


Table 1 (continued)

\begin{tabular}{|c|c|c|c|c|c|c|c|c|c|}
\hline & \multirow[t]{2}{*}{$N$ individuals (\%) } & \multicolumn{2}{|c|}{ Total cost } & \multicolumn{2}{|c|}{$\begin{array}{l}\text { Primary care } \\
\text { cost }\end{array}$} & \multicolumn{2}{|c|}{$\begin{array}{l}\text { General hospital } \\
\text { cost }\end{array}$} & \multicolumn{2}{|c|}{$\begin{array}{l}\text { Mental health } \\
\text { service cost }\end{array}$} \\
\hline & & Mean & SD & Mean & SD & Mean & SD & Mean & SD \\
\hline \multicolumn{10}{|c|}{$\begin{array}{l}\text { Distance from GP practice to nearest inpatient } \\
\text { mental health service }\end{array}$} \\
\hline$>3-6 \mathrm{~km}$ & $3550(25.7)$ & 5172 & 14,852 & 918 & 1323 & 1903 & 8254 & 2351 & 9942 \\
\hline$>6-9 \mathrm{~km}$ & $2563(18.5)$ & 5426 & 15,665 & 878 & 1246 & 1778 & 6592 & 2770 & 11,338 \\
\hline$>9 \mathrm{~km}$ & $5031(36.3)$ & 4525 & 12,709 & 992 & 1481 & 1501 & 5246 & 2031 & 9062 \\
\hline
\end{tabular}

$G P$ general practitioner, $S D$ standard deviation

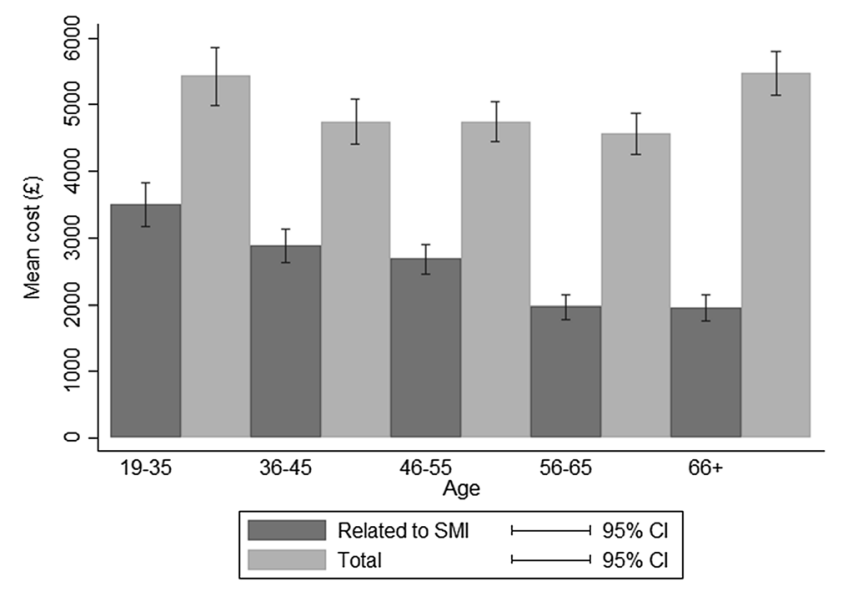

Fig. 1 Mean annual cost over age groups, comparing total costs and related costs. $C I$ confidence interval, SMI serious mental illness and hospital, but those with three or more Charlson index comorbidities had lower specialist mental healthcare costs. Distance from hospital care and inpatient mental healthcare was associated with lower costs in some sectors. Comorbid depression and smoking were associated with higher primary care costs only, and male patients had lower primary care costs.

\subsection{Sensitivity Tests}

As shown in Table 4, if we used average primary care visit duration instead of the visit-specific duration data in CPRD, the mean annual primary care cost was higher ( $£ 985$ instead of £938). Changing the costing of mental health admissions in MHMDS from cluster-specific to weighted cluster average costs had little effect, with mean annual mental health costs increasing from $£ 2334$ to $£ 2354$.

Table 2 Resource utilisation within each sector per year

\begin{tabular}{|c|c|c|c|c|}
\hline \multirow[t]{2}{*}{ Sector } & \multirow[t]{2}{*}{ Resource unit } & \multicolumn{2}{|c|}{ Annual utilisation } & \multirow[t]{2}{*}{ Mean annual cost } \\
\hline & & Mean & Median & \\
\hline \multirow[t]{8}{*}{ Primary care } & GP-face to face clinic visit & 4.8 & 3 & \multirow[t]{6}{*}{$£ 233.27$ (all primary care visits) } \\
\hline & GP-telephone visit & 0.8 & 0 & \\
\hline & GP_face to face home visit/other & 0.2 & 0 & \\
\hline & Nurse—face to face clinic visit & 1.7 & 1 & \\
\hline & Nurse-telephone visit & 0.07 & 0 & \\
\hline & Nurse-face to face home visit/other & 0.05 & 0 & \\
\hline & Tests (pathology, radiology, etc.) & 8.6 & 7 & $£ 52.41$ \\
\hline & Drug prescriptions & 64.4 & 33 & $£ 651.95$ \\
\hline \multirow[t]{5}{*}{ Specialist mental health } & Visits & 13.2 & 0 & \multirow[t]{4}{*}{$£ 900.38$ (outpatient care) } \\
\hline & Day attendances & 0.4 & 0 & \\
\hline & ECT sessions & 0.02 & 0 & \\
\hline & Reviews & 0.9 & 0 & \\
\hline & Mental health inpatient bed days & 4.1 & 0 & $£ 1433.94$ \\
\hline \multirow[t]{2}{*}{ General hospital } & Inpatient bed days in general hospital & 6.6 & 0 & $£ 1654.97$ \\
\hline & A\&E presentations & 0.5 & 0 & $£ 61.95$ \\
\hline
\end{tabular}

$A \& E$ accident and emergency, $E C T$ electroconvulsive therapy, $G P$ general practitioner 
Table 3 Association of patient and practice characteristics with differences in costs by sector (average marginal effects, £ per year)

\begin{tabular}{|c|c|c|c|c|}
\hline & Total costs $(95 \% \mathrm{CI})$ & Primary care $(95 \% \mathrm{CI})$ & General hospital $(95 \% \mathrm{CI})$ & Mental health (95\% CI) \\
\hline \multicolumn{5}{|l|}{ Age } \\
\hline \multicolumn{5}{|l|}{ Base: 19-35 } \\
\hline $36-45$ & $\begin{array}{l}-793.05^{*}(-1553.38,- \\
32.73)\end{array}$ & $\begin{array}{l}221.98 * * *(159.22 \\
284.74)\end{array}$ & $\begin{array}{l}-224.65(-521.59 \\
72.29)\end{array}$ & $\begin{array}{l}-711.27 * *(-1248.39,- \\
174.15)\end{array}$ \\
\hline $46-55$ & $-747.01(1500.54,6.51)$ & $\begin{array}{l}383.46 * * *(318.63 \\
448.29)\end{array}$ & $\begin{array}{l}-167.94(-481.58 \\
145.71)\end{array}$ & $\begin{array}{l}-841.04 * *(1371.16,- \\
310.91)\end{array}$ \\
\hline $56-65$ & $\begin{array}{l}-1140.77 * *(-1878.66 \\
-402.89)\end{array}$ & $\begin{array}{l}421.99 * * *(352.48 \\
491.50)\end{array}$ & $115.06(-213.49,443.62)$ & $\begin{array}{l}-1550.06 * * *(-2059.92 \\
-1040.20)\end{array}$ \\
\hline$\geq 66$ & $\begin{array}{l}-525.11(-1297.68 \\
247.46)\end{array}$ & $\begin{array}{l}389.56 * * *(324.36 \\
454.76)\end{array}$ & $637.17 * *(277.74,996.59)$ & $\begin{array}{l}-1486.22 * * *(-2016.29 \\
-956.16)\end{array}$ \\
\hline \multicolumn{5}{|l|}{ Sex } \\
\hline \multicolumn{5}{|l|}{ Base: female } \\
\hline Male & $68.09(-356.23,492.41)$ & $\begin{array}{l}-215.53 * * *(-259.00,- \\
172.05)\end{array}$ & $76.79(-124.04,277.62)$ & $168.31(-119.27,455.90)$ \\
\hline \multicolumn{5}{|l|}{ Ethnicity } \\
\hline \multicolumn{5}{|l|}{$\begin{array}{l}\text { Base: black, minority } \\
\text { ethnicities }\end{array}$} \\
\hline White & $\begin{array}{l}2369.24 * * *(1941.31 \\
2797.17)\end{array}$ & $\begin{array}{l}315.13 * * *(273.94, \\
356.33)\end{array}$ & $\begin{array}{l}887.96 * * *(660.82 \\
1115.11)\end{array}$ & $\begin{array}{l}1170.84 * * *(891.51, \\
1450.16)\end{array}$ \\
\hline \multicolumn{5}{|l|}{ Diagnostic grouping } \\
\hline \multicolumn{5}{|l|}{$\begin{array}{l}\text { Base: bipolar disorder } \\
\text { and affective psychosis }\end{array}$} \\
\hline $\begin{array}{l}\text { Schizophrenia and other } \\
\text { psychoses }\end{array}$ & $\begin{array}{l}908.29 * * * \\
1319.81)\end{array}$ & $-20.75(-67.60,26.10)$ & $136.83(-57.08,330.73)$ & $\begin{array}{l}803.11 * * *(525.76, \\
1080.45)\end{array}$ \\
\hline Both categories & $\begin{array}{c}2380.38 * * *(1647.39 \\
3113.36)\end{array}$ & $104.60 * *(30.15,179.06)$ & $294.28 *(26.11,562.45)$ & $\begin{array}{l}2021.41 * * *(1490.72, \\
2552.09)\end{array}$ \\
\hline \multicolumn{5}{|l|}{ Years since diagnosis } \\
\hline \multicolumn{5}{|l|}{ Base: 0-1 } \\
\hline $2-5$ & $\begin{array}{l}-569.40(-1315.91 \\
177.11)\end{array}$ & $27.27(-47.66,102.20)$ & $\begin{array}{l}-182.67(-521.71, \\
156.35)\end{array}$ & $-441.74(-953.49,70.01)$ \\
\hline$>5$ & $\begin{array}{l}-460.57(-1,142.22, \\
221.07)\end{array}$ & $-6.91(-69.33,55.52)$ & $\begin{array}{l}-121.38(-454.87 \\
212.11)\end{array}$ & $-376.78(-835.60,82.04)$ \\
\hline \multicolumn{5}{|l|}{$\begin{array}{l}\text { Index of multiple depriva- } \\
\text { tion quintile }\end{array}$} \\
\hline \multicolumn{5}{|l|}{ Base: 1, least deprived } \\
\hline 2 & $230.72(-404.09,865.53)$ & $21.49(-44.36,87.33)$ & $129.43(-154.57,413.43)$ & $78.77(-361.85,519.39)$ \\
\hline 3 & $870.90 *(163.05,1578.75)$ & $59.21(-9.33,127.75)$ & $301.40(-7.32,610.13)$ & $506.87 *(4.71,1009.04)$ \\
\hline 4 & $759.92 *(109.43,1410.41)$ & $129.96 * * *(65.20,194.72)$ & $227.27(-66.68,521.23)$ & $418.83(-33.13,869.98)$ \\
\hline 5 , most deprived & $\begin{array}{l}1036.13 * *(345.86 \\
1726.40)\end{array}$ & $150.45^{* * *}(82.58,218.33)$ & $304.18(-29.04,637.40)$ & $580.50 *(117.98,1043.03)$ \\
\hline \multicolumn{5}{|l|}{$\begin{array}{l}\text { Number of Charlson } \\
\text { comorbidities }\end{array}$} \\
\hline \multicolumn{5}{|l|}{ Base: 0} \\
\hline 1 & $\begin{array}{l}707.23 * *(250.80 \\
1163.66)\end{array}$ & $\begin{array}{l}357.91 * * *(307.08 \\
408.75)\end{array}$ & $\begin{array}{l}490.85 * * *(273.77 \\
707.92)\end{array}$ & $-144.03(-450.18,162.12)$ \\
\hline 2 & $\begin{array}{l}1926.56 * *(803.36 \\
3049.77)\end{array}$ & $\begin{array}{l}766.61 * * *(645.79 \\
887.42)\end{array}$ & $\begin{array}{l}1252.16^{* * *}(571.71 \\
1932.60)\end{array}$ & $\begin{array}{l}-360.09(-1040.44 \\
320.26)\end{array}$ \\
\hline 3 or more & $\begin{array}{c}1823.86 * * \\
2999.76)\end{array}$ & $\begin{array}{c}926.39 * * * \\
1115.79)\end{array}$ & $\begin{array}{l}1308.09 * * *(782.10 \\
1978.08)\end{array}$ & $\begin{array}{l}-1036.79 *(-1885.43,- \\
188.14)\end{array}$ \\
\hline \multicolumn{5}{|l|}{ Comorbid depression } \\
\hline \multicolumn{5}{|l|}{$\begin{array}{l}\text { Base: no history of } \\
\text { depression }\end{array}$} \\
\hline History of depression & $19.10(-419.18,457.39)$ & $\begin{array}{l}215.82 * * *(172.21 \\
259.42)\end{array}$ & $\begin{array}{l}-23.14(-224.60, \\
178.33)\end{array}$ & $-158.88(-457.99,140.23)$ \\
\hline
\end{tabular}


Table 3 (continued)

Total costs $(95 \% \mathrm{CI}) \quad$ Primary care $(95 \% \mathrm{CI}) \quad$ General hospital $(95 \% \mathrm{CI}) \quad$ Mental health $(95 \% \mathrm{CI})$

\begin{tabular}{|c|c|c|c|c|}
\hline \multicolumn{5}{|l|}{ History of smoking } \\
\hline \multicolumn{5}{|l|}{ Base: non-smoker } \\
\hline Current or ex-smoker & $-3.71(-539.19,531.78)$ & $\begin{array}{l}143.87 * * * * \\
187.33)\end{array}$ & $\begin{array}{l}-84.41(-362.75 \\
193.93)\end{array}$ & $-54.61(-413.59,304.38)$ \\
\hline \multicolumn{5}{|l|}{ Rurality of GP practice } \\
\hline \multicolumn{5}{|l|}{ Base: urban area } \\
\hline Rural area & $\begin{array}{l}409.92(-1033.33 \\
213.29)\end{array}$ & $77.99(-0.77,156.75)$ & $\begin{array}{l}-87.46(-337.37 \\
161.46)\end{array}$ & $-435.28(-878.18,7.61)$ \\
\hline \multicolumn{5}{|c|}{$\begin{array}{l}\text { Distance from GP practice } \\
\text { to nearest acute hospital }\end{array}$} \\
\hline \multicolumn{5}{|l|}{ Base: $0-3 \mathrm{~km}$} \\
\hline$>3-6 \mathrm{~km}$ & $343.94(-833.53,145.64)$ & $\begin{array}{l}-82.61 * *(-132.44,- \\
32.78)\end{array}$ & $-192.28(-411.09,26.52)$ & $-65.42(-402.70,271.86)$ \\
\hline$>6-9 \mathrm{~km}$ & $\begin{array}{l}-234.69(-960.93 \\
491.56)\end{array}$ & $38.42(-38.21,115.06)$ & $\begin{array}{l}-55.75(-383.34 \\
271.83)\end{array}$ & $-245.01(-761.12,271.10)$ \\
\hline$>9 \mathrm{~km}$ & $104.58(795.64,586.48)$ & $-34.01(-107.66,39.65)$ & $\begin{array}{l}-161.97(-454.13 \\
130.20)\end{array}$ & $90.33(418.36,599.03)$ \\
\hline \multicolumn{5}{|c|}{$\begin{array}{l}\text { Distance from GP practice } \\
\text { to nearest inpatient men- } \\
\text { tal health service }\end{array}$} \\
\hline \multicolumn{5}{|l|}{ Base: $0-3 \mathrm{~km}$} \\
\hline$>3-6 \mathrm{~km}$ & $\begin{array}{l}-21.83(-674.61 \\
630.94)\end{array}$ & $27.51(-33.92,88.94)$ & $-1.65(-333.31,330.01)$ & $-53.14(-475.30,369.03)$ \\
\hline$>6-9 \mathrm{~km}$ & $241.69(-502.12,985.50)$ & $-27.70(-90.92,35.51)$ & $\begin{array}{l}-118.67(-436.04 \\
198.70)\end{array}$ & $368.97(-143.07,881.01)$ \\
\hline$>9 \mathrm{~km}$ & $615.16(-1269.50,39.16)$ & $43.53(-23.31,110.38)$ & $\begin{array}{l}-402.93 * *(-690.61,- \\
115.26)\end{array}$ & $-242.43(-693.57,208.71)$ \\
\hline
\end{tabular}

Marginal effects from GLM with Poisson distribution and log link with individual random effects

$C I$ confidence interval, GLM generalised linear model, GP general practitioner

${ }^{*} p<0.05, * * p<0.01, * * * p<0.001$

The set of models with an interaction term between sex and diagnostic grouping found the interaction between male sex and "schizophrenia and other psychoses" to be positive and statistically significant in the models for total costs and mental health costs. The marginal effects from this model presented in Supplementary Table 4 show a larger difference in costs between the base category of "bipolar disorder and affective psychoses" and "schizophrenia and other psychoses" for males than females.

\section{Discussion}

Estimates of healthcare costs for people with SMI are required to inform resource allocation, to model resource consumption in health technology assessments, and for service planning. Previous analyses of healthcare costs for people with SMI have focused on specific sectors of the healthcare system, offering only a partial picture of overall resource use. Furthermore, there are no published costing algorithms for SMI care in the English NHS, which may explain the limited availability of costing studies in this population. To address these issues, we have developed a micro-costing methodology to estimate the cost of healthcare services used by people with SMI across primary, general hospital and mental healthcare settings in England. We applied this methodology to linked individual-level data to study the determinants of annual healthcare costs for a sample of people with SMI over a 3-year period. To our knowledge, this is the first study to use linked patient-level data from electronic health records to study cost variation within the SMI population.

We estimate average annual care costs of $£ 4989$ per patient (in 2013/14 terms, equivalent to $£ 5777$ in 2019 terms adjusted using the consumer price index). [48] This is substantially higher than the average annual cost of $£ 1631$ for a member of the general public of similar age to our study average (52 years) [49]. Assuming a point prevalence of SMI of $0.9 \%$ and a total population of 54.3 million in 2014 [50], the total annual cost to the English NHS is $£ 2.44$ billion 
Table 4 Effect of alternate specifications on sectoral cost distributions

\begin{tabular}{llll}
\hline & Main analysis & Sensitivity A & Sensitivity B \\
\hline $\begin{array}{l}\text { Total costs } \\
\text { Mean (SD) }\end{array}$ & $4989(14,348)$ & $5036(14,350)$ & $5009(14,464)$ \\
Median & 1208 & 1266 & 1208 \\
Primary care costs & & & \\
Mean (SD) & $938(1368)$ & $985(1386)$ & \\
Median & 531 & 574 & $18.7 \%$ \\
$\%$ of total costs & $18.8 \%$ & $19.6 \%$ & \\
General hospital costs & $1717(6734)$ & & $34.3 \%$ \\
Mean (SD) & 0 & & $2354(10,146)$ \\
Median & $34.4 \%$ & $34.1 \%$ & 0 \\
\% of total costs & & & $47.0 \%$ \\
Specialist mental health costs & $2334(10,021)$ & & \\
Mean (SD) & 0 & $46.3 \%$ & \\
Median & $46.8 \%$ & & \\
$\%$ of total costs & & & \\
\hline
\end{tabular}

Sensitivity A: Assumes average duration for all primary care visits as per the 2006/07 UK General Practice Work Load Survey. Sensitivity B: Uses weighted average cost per bed day across clusters from the national Reference Costs for specialist mental health admissions, rather than cluster-specific costs

$S D$ standard deviation (equivalent to $£ 2.82$ billion in 2019 terms). Previous estimates for schizophrenia and bipolar disorder separately were higher (approximately $£ 2.6$ billion and $£ 1.9$ billion, respectively, in 2013/14 terms) [51, 52], but were prevalence-based rather than based on individual-level data linked across NHS services.

Costs are highest in the first 12 months after diagnosis and then fall by approximately $11-13 \%$ in subsequent years, which is consistent with the patterns observed for other health conditions [53]. This may be due to higher service use during the treatment initiation period following diagnosis, reduced risk of subsequent crisis events, dropout from treatment, or gradual adaptation by patients to their health condition. Moreover, treatment costs can be predicted by several patient characteristics such as local area deprivation and ethnicity. While most of these characteristics have a consistent directional effect across sectors, older age is associated with higher costs in primary care but lower costs in specialised mental healthcare, suggesting a cross-sectoral shift in the cost burden over a patient's lifetime. Age and diagnostic category were also strong predictors of cost in Wolff et al. [23], albeit the studies included in that review did not include only SMI patients and focused only on inpatient care.

The primary strength of our study is the use of linked longitudinal electronic health records covering primary, secondary and community care, which allows us to implement a micro-costing approach to obtain detailed resource use estimates. These data have only recently become available and provide a comprehensive view of contemporaneous care arrangements in the English routine care setting.
There are a number of limitations to our study that arise from the specific data used. The data do not cover (nonadmitted) outpatient care provided by general hospitals, drugs prescribed by community mental health services, or all social care provided in the community. These cost categories are likely to be important as payers are increasingly starting to pool budgets across sectors. The data did not include costs of seeking healthcare (such as travel) or care outside the NHS, nor measures of disease severity, so we cannot ascertain whether severity mediates the association between costs and factors such as socioeconomic status. While GP practices participating in CPRD have been shown to be broadly representative in terms of the age-sex composition and socio-economic profile of their patient population, we cannot ascertain the representativeness of our specific sample, which may be compromised by the more transient nature of care relationships for people with SMI, who are often living in precarious circumstances, and the requirement to be registered with the practice for at least 1 year prior to sample inclusion. The NHS requires patients to be registered with a GP, so we are unlikely to be missing patients managed solely by specialist mental health services. In MHMDS, there was an imperfect correlation between dates assigned for episodes of care (cluster episodes) and dates when healthcare activities were recorded. Moreover, in some instances, patients were recorded to be in hospital while receiving outpatient care. We made the assumption that cluster episode dates were more likely to be wrong and that recorded activities were genuine, which may have led to overestimated costs. 
The measurement of visit costs was imprecise due to the absence of band-specific hourly costs for nurses in the PSSRU cost estimates (with all nurses in primary care classified as band 5), and recording errors of visit duration in CPRD. However, our use of the timing of file opening and closing in CPRD does produce estimates that correlate well with duration data available from other sources, and has now been incorporated into the PSSRU unit cost estimates [41]. This analysis is conducted on data from 2011/12 to $2013 / 14$, using unit costs for $2013 / 14$. While we have inflated the average costs to current values using national consumer price inflation figures for the health domain [48], other changes may have occurred over that period not in line with inflation.

\section{Conclusions}

Estimates of the direct cost of SMI are important for decision makers seeking to improve technical and allocative efficiency of care services. Information from this study can help decision makers in planning services and benchmarking as well as resource allocation. Our study demonstrates that the cost of healthcare resource use across primary, secondary and community care are determined by a range of patient characteristics that are observable in electronic health records. Specialised mental healthcare is the main component of annual costs for people with SMI.

Author Contributions All authors contributed to the design of the study. JR coded the primary care data, PK coded the hospital data, and MJAA coded the specialist mental health data. JR conducted the statistical analysis overall, with input from the other authors. All authors contributed to the drafting of the manuscript and its revision and approved the final version of the manuscript. All authors provided critical feedback and informed the analysis and manuscript.

Data Availability Statement The datasets used in this study were accessed via the Clinical Practice Research Datalink (CPRD) for the current study only and are not publicly available due to the confidential nature of the healthcare data involved, with this restriction determined by CPRD.

\section{Compliance with Ethical Standards}

Funding This project was part funded by the National Institute for Health Research (NIHR) Health Services and Delivery Research programme (project number 13/54/40). The views expressed are those of the author(s) and not necessarily those of the NHS, the NIHR or the Department of Health. It is also part-funded by the Health Foundation's Efficiency Research Programme. The Health Foundation is an independent charity committed to bringing about better health and healthcare for people in the UK.

Conflict of interest Jemimah Ride, Panagiotis Kasteridis, Nils Gutacker, Maria Jose Aragon Aragon, and Rowena Jacobs declare no competing interests.
Open Access This article is distributed under the terms of the Creative Commons Attribution-NonCommercial 4.0 International License (http://creativecommons.org/licenses/by-nc/4.0/), which permits any noncommercial use, distribution, and reproduction in any medium, provided you give appropriate credit to the original author(s) and the source, provide a link to the Creative Commons license, and indicate if changes were made.

\section{References}

1. Department of Health. No health without mental health: a crossgovernment mental health outcomes strategy for people of all ages. HMSO London; 2011.

2. NHS Employers. Quality and outcomes framework. 2019. https:// www.nhsemployers.org/pay-pensions-and-reward/primary-carecontacts/general-medical-services/quality-and-outcomes-frame work. Accessed 19 Aug 2019.

3. Saha S, Chant D, Welham J, McGrath J. A systematic review of the prevalence of schizophrenia. PLoS Med. 2005;2(5):e141.

4. Pini S, de Queiroz V, Pagnin D, Pezawas L, Angst J, Cassano $\mathrm{GB}$, et al. Prevalence and burden of bipolar disorders in European countries. Eur Neuropsychopharmacol. 2005;15(4):425-34.

5. Chang C-K, Hayes RD, Perera G, Broadbent MT, Fernandes AC, Lee WE, et al. Life expectancy at birth for people with serious mental illness and other major disorders from a secondary mental health care case register in London. PLoS One. 2011;6(5):e19590.

6. De Hert M, Correll CU, Bobes J, Cetkovich-Bakmas M, Cohen D, Asai I, et al. Physical illness in patients with severe mental disorders I Prevalence, impact of medications and disparities in health care. World Psychiatry Off J World Psychiatr Assoc. 2011;10(1):52-77.

7. Brown S, Kim M, Mitchell C, Inskip H. Twenty-five year mortality of a community cohort with schizophrenia. Br J Psychiatry. 2010;196(2):116-21.

8. Woodhead C, Ashworth M, Schofield P, Henderson M. Patterns of physical co-/multi-morbidity among patients with serious mental illness: a London borough-based cross-sectional study. BMC Fam Pract. 2014;15(1):117.

9. Wahlbeck K, Westman J, Nordentoft M, Gissler M, Laursen TM. Outcomes of Nordic mental health systems: life expectancy of patients with mental disorders. Br J Psychiatry. 2011;199(6):453-8.

10. Hackman AL, Goldberg RW, Brown CH, Fang LJ, Dickerson FB, Wohlheiter K, et al. Use of emergency department services for somatic reasons by people with serious mental illness. Psychiatr Serv. 2006;57(4):563-6.

11. Merrick EL, Perloff J, Tompkins CP. Emergency department utilization patterns for Medicare beneficiaries with serious mental disorders. Psychiatr Serv. 2010;61(6):628-31.

12. Schoenbaum M, Sutherland JM, Chappel A, Azrin S, Goldstein AB, Rupp A, et al. Twelve-month health care use and mortality in commercially insured young people with incident psychosis in the United States. Schizophr Bull. 2017;43(6):1262-72.

13. Lally J, Wong YL, Shetty H, Patel A, Srivastava V, Broadbent MT, et al. Acute hospital service utilization by inpatients in psychiatric hospitals. Gen Hosp Psychiatr. 2015;37(6):577-80.

14. Lee S, Black D, Held M. Associations of multiplicity of comorbid health conditions, serious mental illness, and health care costs. Soc Work Health Care. 2016;55(7):518-30.

15. Marcellusi A, Fabiano G, Viti R, Francesa Morel PC, Nicolò G, Siracusano A, et al. Economic burden of schizophrenia in Italy: 
a probabilistic cost of illness analysis. BMJ Open. 2018. https:// doi.org/10.1136/bmjopen-2017-018359

16. Gupta RD, Guest JF. Annual cost of bipolar disorder to UK society. Br J Psychiatry. 2002;180(3):227-33.

17. Goeree R, Farahati F, Burke N, Blackhouse G, O'Reilly D, Pyne $\mathrm{J}$, et al. The economic burden of schizophrenia in Canada in 2004. Curr Med Res Opin. 2005;21(12):2017-28.

18. Behan C, Kennelly B, O'Callaghan E. The economic cost of schizophrenia in Ireland: a cost of illness study. Ir J Psychol Med. 2008;25(3):80-7.

19. Knapp M, Mangalore R, Simon J. The global costs of schizophrenia. Schizophr Bull. 2004;30(2):279-93.

20. Evers SM, Ament AJ. Costs of schizophrenia in the Netherlands. Schizophr Bull. 1995;21(1):141-53.

21. Hewlett E, Moran V. Making mental health count: the social and economic costs of neglecting mental health care. OECD health policy studies. Paris: OECD Publishing; 2014.

22. Young AH, Rigney U, Shaw S, Emmas C, Thompson JM. Annual cost of managing bipolar disorder to the UK healthcare system. J Affect Disord. 2011;133(3):450-6.

23. Wolff J, McCrone P, Koeser L, Normann C, Patel A. Cost drivers of inpatient mental health care: a systematic review. Epidemiol Psychiatr Sci. 2015;24(1):78-89.

24. Senese F, Rucci P, Fantini MP, Gibertoni D, Semrov E, Nassisi M, et al. Measuring costs of community mental health care in Italy: a prevalence-based study. Eur Psychiatry. 2018;51:34-41.

25. de Oliveira C, Cheng J, Vigod S, Rehm J, Kurdyak P. Patients with high mental health costs incur over 30 percent more costs than other high-cost patients. Health Aff. 2016;35(1):36-43.

26. Herrett E, Gallagher AM, Bhaskaran K, Forbes H, Mathur R, van Staa T, et al. Data resource profile: clinical Practice Research Datalink (CPRD). Int J Epidemiol. 2015;44(3):827-36.

27. Campbell J, Dedman DJ, Eaton SC, Gallagher AM, Williams TJ. Is the CPRD Gold population comparable to the UK population? Pharmacoepidemiol Drug Saf. 2013;22:280-1.

28. Chisholm J. The Read clinical classification. BMJ Br Med J. 1990;300(6732):1092.

29. Curtis L. Unit costs of health and social care 2014. Canterbury: Personal Social Services Research Unit, University of Kent; 2014.

30. Westcott $R$. The length of consultations in general practice. JR Coll Gen Pract. 1977;27(182):552-5.

31. McCabe R, Khanom H, Bailey P, Priebe S. Shared decisionmaking in ongoing outpatient psychiatric treatment. Patient Educ Couns. 2013;91(3):326-8.

32. Fleury M-J, Imboua A, Aubé D, Farand L, Lambert Y. General practitioners' management of mental disorders: a rewarding practice with considerable obstacles. BMC Fam Pract. 2012;13(1):19.

33. Waterreus A, Morgan VA. Treating body, treating mind: the experiences of people with psychotic disorders and their general practitioners-findings from the Australian National Survey of High Impact Psychosis. Aust N Z J Psychiatry. 2018;52(6):561-72.

34. Joint Formulary Committee. British national formulary (BNF) 66. London: Pharmaceutical Press; 2013.

35. Department of Health. NHS reference costs 2013 to 2014. London: Department of Health; 2014.

36. The Health Informatics Service. Electronic Staff Record. 2018. http://www.electronicstaffrecord.nhs.uk/home/. Accessed 11 Dec 2018.
37. Financial Planning, Monitoring and Analysis Team. Hospital and community health services pay and price inflation series. 2016. http://www.info.doh.gov.uk/doh/finman.nsf/af3d43e36a 4c8f8500256722005b77f8/360a47827991d10a802580360 02d8d9f/\$FILE/2015.16\%20Pay\%20\&\%20Price\%20series.xlsx. Accessed 11 Dec 2018.

38. NHS England. Guidance on mental health currencies and payments. NHS England; 2013

39. NHS. NHS Data Dictionary 2019. https://www.datadictionary. nhs.uk/data_dictionary/nhs business_definitions/a/adult menta 1_health_clustering_tool_de.asp?shownav $=1$ ?query $=\% 22 \mathrm{men}$ tal + health + clustering + tool $\% 22 \&$ rank $=100 \&$ shownav $=1$. Accessed $21 \mathrm{Feb} 2019$.

40. NHS Digital. Costing grouper. NHS Digital. https://webarchive .nationalarchives.gov.uk/20171012081434/http://content.digit al.nhs.uk/article/2609/HRG4-201112-Reference-Costs-Grouper. Accessed 1 Nov 2019.

41. Curtis CJ, Burns A. Unit costs of health and social care 2017. Canterbury: Personal Social Services Research Unit, University of Kent; 2017.

42. Morris S, Sutton M, Gravelle H. Inequity and inequality in the use of health care in England: an empirical investigation. Soc Sci Med. 2005;60(6):1251-66.

43. Manning WG, Mullahy J. Estimating log models: to transform or not to transform? J Health Econ. 2001;20(4):461-94.

44. Pregibon D. Goodness of link tests for generalized linear models. Appl Stat. 1980;29(1)15-24.

45. StataCorp. Stata statistical software: release 14. College Station: StataCorp LLC; 2015.

46. Abel KM, Drake R, Goldstein JM. Sex differences in schizophrenia. Int Rev Psychiatry. 2010;22(5):417-28.

47. Diflorio A, Jones I. Is sex important? Gender differences in bipolar disorder. Int Rev Psychiatry. 2010;22(5):437-52.

48. Office for National Statistics. Consumer price inflation detailed reference tables, 18 September 2019. London: Office for National Statistics; 2019

49. Asaria M. Health care costs in the English NHS: reference tables for average annual NHS spend by age, sex and deprivation group. CHE research paper. York: Centre for Health Economics, University of York; 2017.

50. ONS. Population estimates for the UK, England and Wales, Scotland and Northern Ireland: mid-2014. https://www.ons.gov.uk/ peoplepopulationandcommunity/populationandmigration/popul ationestimates/datasets/populationestimatesforukenglandandw alesscotlandandnorthernireland. Accessed 1 Nov 2019.

51. Mangalore R, Knapp M. Cost of schizophrenia in England. The J Ment Health Policy Econ. 2007;10(1):23-41.

52. McCrone PR, Dhanasiri S, Patel A, Knapp M, Lawton-Smith S. Paying the price: the cost of mental health care in England to 2026. London: King's Fund; 2008.

53. Walker S, Asaria M, Manca A, Palmer S, Gale CP, Shah AD, et al. Long-term healthcare use and costs in patients with stable coronary artery disease: a population-based cohort using linked health records (CALIBER). Eur Heart J Qual Care Clin Outcomes. 2016;2(2):125-40. 